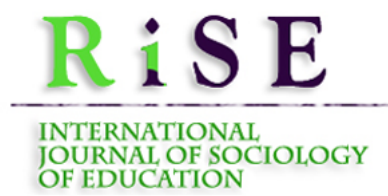

Hipatia Press

www.hipatiapress.com

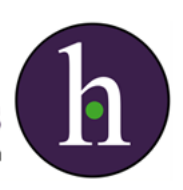

Instructions for authors, subscriptions and further details:

http://rise.hipatiapress.com

\title{
El Sentido de las Becas para los Estudiantes Universitarios de Clases Populares. Impacto Del Nuevo Sistema de Becas en la Universidad Española
}

Delia Langa-Rosado ${ }^{1}$

1) Universidad de Jaén, Spain

Date of publication: June $25^{\text {th }}, 2019$

Edition period: June 2019-October 2019

To cite this article: Langa-Rosado, D. (2019). El Sentido de las Becas para los Estudiantes Universitarios de Clases Populares. Impacto Del Nuevo Sistema de Becas en la Universidad Española, International Journal of Sociology of Education, 8(2), 105-126. doi: 10.17583/rise.2019.3802

To link this article: http://dx.doi.org/10.17583/rise.2019.3802

\section{PLEASE SCROLL DOWN FOR ARTICLE}

The terms and conditions of use are related to the Open Journal System and to Creative Commons Attribution License (CC-BY) 

June 2019 pp. 105-126

\section{The Meaning of Grants for Working Class University Students. Impact of the New Financial Aid University System in Spanish University}

Delia Langa-Rosado

Universidad de Jaén

(Received: 9 October 2018; Accepted: 29 April 2019; Published: 25 June 2019)

\section{Abstract}

Since 2013, university financial aids in Spain have shifted towards a more competitive system, being increasingly dependent on educational achievement. In this paper we have approached to grant-holders' experiences by means of the interpretation of working-class students' discourses. We aimed to describe their "practical reasons" and to make more comprehensible the ways of facing these more demanding institutional rules. Grant-holders have been traditionally a very dependent group on achievement when taking decisions along their careers, even before starting their studies. We have appreciated that present changes increase this dependence, that is experienced in many cases as new ways of pressure, contradiction and uncertainty. We can see nowadays that the university option is less and less attractive for this kind of students and this fact may be connected with the drop in the number of students after the recent university policies.

Keywords: university students, inequality, social class, grants. 

June 2019 pp. 105-126

\section{El Sentido de las Becas para los Estudiantes Universitarios de Clases Populares. Impacto Del Nuevo Sistema de Becas en la Universidad Española}

Delia Langa-Rosado

Universidad de Jaén

(Recibido: 9 Octubre 2018; Aceptado: 29 Abril 2019; Publicado: 25 Junio 2019)

\section{Resumen}

En España las becas universitarias han virado a partir de 2013 hacia un sistema más competitivo y dependiente de los resultados académicos. En este trabajo hemos abordado, a partir del análisis del discurso de estudiantes universitarios de orígenes populares, sus experiencias como becarios en este contexto de nuevas exigencias. Pretendíamos acercarnos y describir las "razones prácticas" de los estudiantes y hacer más comprensible los modos de posicionarse ante las cambiantes reglas institucionales. Los becarios han sido siempre un colectivo especialmente dependiente del logro en sus decisiones a lo largo de la carrera, y antes incluso, en las elecciones iniciales. Hemos apreciado cómo los actuales cambios no hacen sino incrementar esta dependencia, que se vive en muchos casos en forma de nuevas presiones, contradicciones e incertidumbres. Se observa en general cómo hoy la apuesta universitaria se ha vuelto menos atractiva para este tipo de estudiantes, lo que conecta, pensamos, con la caída en el censo universitario que se viene registrando tras la implementación de las nuevas políticas universitarias.

Palabras clave: estudiantes universitarios, desigualdad, clases sociales, becas. 


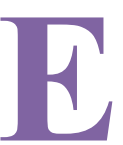

n los últimos años en la universidad española se viene apuntalando una tendencia que desde mediados de los 90 caracteriza a las políticas educativas de buena parte de países de la OCDE (Delapierre, 2015), y que se orienta a aumentar la financiación privada del gasto educativo. Como consecuencia de las medidas de ahorro del gasto educativo del Real Decreto ley 14/2012, los precios de los estudios universitarios, aunque con importantes diferencias territoriales (Ariño, 2014), experimentaron un incremento del $32 \%$ en los grados y del $75 \%$ en los másteres ${ }^{1}$, modificándose además en el sentido de diferenciarse según el rendimiento académico (Sacristán, 2014). Contrariamente a lo que cabría esperar tras el aumento de las tasas, en el sistema de becas, especialmente a partir de 2013, hemos asistido a un profundo giro que sin duda añade nuevas dificultades, especialmente a los estudiantes de orígenes populares. Se ha pasado a condicionar más la obtención de ayudas al logro del estudiante, lo que parece dejar en un segundo plano la finalidad de la igual de oportunidades priorizando en cambio el criterio de una supuesta mayor eficiencia (Río et al., 2015). Hernández Armenteros y Pérez García (2017) señalan que más de 70.000 estudiantes por curso académico se han visto afectados por los nuevos criterios y no han podido acceder o mantener la condición de becario. Por otra parte, el porcentaje de los que sólo han tenido derecho a matrícula ha subido del $12 \%$ al $34 \%$. El proceso de asignación de becas, al priorizar además que el gasto público quede restringido a lo inicialmente presupuestado, se hace no sólo competitivo, sino en cualquier caso más complejo e incierto para el becario, que recibe en distintas fases lo correspondiente a diversos componentes cuyo monto total no llega a conocer hasta el final del curso. Todo esto se ha visto acompañado además una disminución de la cuantía percibida (un $30 \%$ en estos últimos años, mayor, de un $49,5 \%$ para los perceptores de menor capacidad económica, los de umbral 1 de renta), resultante de haberse incrementado el número de becarios disminuyendo a la vez el importe del presupuesto destinado a becas. Es necesario además señalar que la cobertura de nuestro sistema de becas no es muy amplia, llegando a beneficiar a tan sólo algo más de uno de cada cuatro estudiantes, siendo de otro lado muy minoritarios $(4,8 \%)$ los que reciben grandes ayudas, superiores a los 3.500 euros.

Lo realmente novedoso del nuevo sistema no es que el estudiante tenga que rendir cuentas, pues el resultado académico siempre ha sido un factor en 


\section{Langa-Rosado-Becas y Estudiantes de Clases Populares}

la consecución y mantenimiento de las becas. De hecho, sabemos que uno de los más claros efectos de las becas es el de que suelen incrementar la dedicación al estudio (Río Ruiz, 2014; Río Ruiz y Jiménez Rodrigo, 2014; Berlanga et al. 2018). Hernández Armenteros y Pérez García (2014), indican que los becarios tardan de media 5,2 años en terminar su carrera y los no becarios 7,2. Según los Datos y Cifras del SUE curso 2015-16 las tasas de rendimiento ${ }^{2}$ de los becarios son de $87,6 \%$ mientras que las de los no becarios de un $73,4 \%$. A su vez la tasa de éxito es para los primeros de un $92 \%$ y para los segundos un $85 \%$, mientras que la tasa de evaluación ${ }^{4}$, de un 95\% para los becarios y un $85 \%$ para los no becarios. Los primeros no sólo rinden más académicamente, sino que tienen una mayor tendencia a dar cuenta de aquellas asignaturas en las que se matriculan, o dicho de otro modo, muestran un mayor compromiso académico.

Lo novedoso es el carácter claramente competitivo en que se torna el sistema. Tengamos en cuenta, en este sentido, que este giro "eficientista" afecta a estudiantes cuya dependencia del logro académico está sobradamente probada, tanto en las fases previas a la entrada en la universidad como a lo largo de la carrera. Así sabemos que para los chicos de clase obrera la conformación de expectativas educativas depende en mayor medida de los resultados escolares que los de clase media, que mantienen sus aspiraciones incluso en caso de no exitosas trayectorias (Torío López et al., 2007; Martínez García, 2014; Torrents, 2016; Martín Criado y Gómez Bueno, 2017). Esto guarda relación con el hecho de que en la decisión de realizar estudios universitarios se tenga más en cuenta la trayectoria previa como garantía de éxito (Langa-Rosado, 2018; Torrents, 2015). El estilo evitador del riesgo predispone, por otra parte, a optar por titulaciones más cortas y/o fáciles (Mingat y Eicher, 1982; Langa-Rosado Rosado y Río-Ruiz, 2013; Callender y Jackson, 2008; Triventi, 2011; Troiano y Elías, 2013; Troiano et al., 2017), como forma de asegurar el logro educativo. De otro lado, existe constancia de que los estudiantes de orígenes populares implementan en mayor medida conductas, si se pierde la condición de becario, $\mathrm{o}$ ante la insuficiencia de las becas, de compatibilización de estudios y trabajo (Metcalf, 2003; Triventi, 2014; Finkel y Barañano, 2014; Langa-Rosado Rosado, 2015), y de abandono en el peor de los casos (Archer et al., 2003; Cabrera et al., 2006a y 2006b; Villar, 2010; Isleib, 2017; Langa-Rosado Rosado, 2018). Todo ello no hace sino 
poner de manifiesto una más clara dependencia del logro como motivo justificador de la continuidad de la apuesta universitaria en los estudiantes de clases populares frente a los de posiciones más privilegiadas que tienen más "naturalizada" la opción de cursar estudios universitarios (Reay et al., 2005).

Endurecer, pues, las condiciones para acceder a una beca universitaria y conservarla, en un nuevo contexto económico, de crisis y empobrecimiento de muchas familias, aún más las de menos capital económico y cultural, y con unos precios de matrícula mucho más caros, obviamente genera un panorama más desfavorable para los estudiantes de posiciones sociales más bajas. Sabemos que a partir del curso 2012-13 se estancan las tasas de acceso a la Universidad, que venían creciendo desde el inicio de la actual crisis como consecuencia de la disminución de los costes de oportunidad (Carabaña, 2018). Aún más notable es el descenso del censo universitario a partir de este mismo año, y sobre todo si atendemos a los alumnos de grado y/o primer y segundo ciclo, pues en los másteres la tendencia creciente continúa hasta la actualidad ${ }^{5}$. Si vamos al Anuario de Indicadores universitarios del Ministerio de Educación, Cultura y Deporte (en línea) se aprecia un descenso de 149.322 estudiantes entre los cursos 12-13 y 16-17. Habrá que concretar los perfiles sociales de los que están dejando de venir o están abandonando la universidad para avanzar en identificar el impacto de los recientes cambios institucionales en los jóvenes de clases populares. Herrera Cuesta (2019) señala en este sentido una caída de entre 4 puntos y medio y 7 en la representación en el porcentaje que suponen los estudiantes de más bajo nivel socioeconómico entre el curso 2011 y el 2015-16. Por otra parte, Troiano y Torrents (2018) apuntan, para el caso de las universidades catalanas, un descenso en los estudiantes menos tradicionales, en concreto los procedentes de los módulos de F.P., de los mayores de 25 años, así como de aquellos con familias de menos capital cultural.

En este nuevo contexto por tanto cobra aún más importancia la investigación sobre lo que se ha dado en llamar la dimensión social de la Universidad. $\mathrm{Y}$ en concreto parece muy pertinente seguir profundizando, desde distintos ángulos, en los estudios que aborden las condiciones y los efectos del sistema de becas como garante del principio de equidad. 


\section{Langa-Rosado-Becas y Estudiantes de Clases Populares}

\section{Objetivo y Metodología.}

Con el trabajo del que aquí damos cuenta nos hemos querido acercar a esta realidad de un modo interpretativo. Nuestra aportación intentará arrojar luz sobre las lógicas subjetivas, las "razones prácticas" (Bourdieu, 1997) de los sujetos de una concreta posición social. Lo que pretendíamos era acercarnos a los marcos de sentido desde los que los propios estudiantes habían conformado sus decisiones y hecho razonables sus apuestas, prácticas y experiencias en la universidad. En concreto queríamos indagar sobre los significados que tienen las becas para los estudiantes de clases populares y cómo han vivido y se representan los recientes cambios.

Esta investigación ${ }^{6}$ ha partido de la realización de 31 entrevistas que han tenido lugar en el curso 2015-16 entre estudiantes de clases populares de la Universidad de Jaén (UJA) ${ }^{7}$. La muestra la han compuesto: 14 estudiantes de clase obrera rural, 5 estudiantes de clase obrera de X capital, 8 hijos de autónomos manuales, de pueblos de Jaén, y cuatro estudiantes de clase media que hemos utilizado como casos de contraste. Todos los estudiantes de clases populares han sido becarios, 15 de ellos sin interrupción y 12 intermitentemente. En todos los casos se trataba de jóvenes, chicos y chicas en similar proporción (16 universitarias y 15 universitarios), representativos de la oferta de estudios de la UJA (10 estudiantes de algún grado de Ciencias Sociales, 8 de Humanidades o Educación, 7 de alguna Ingeniería, 4 de Ciencias, y 2 de Ciencias de la Salud). Con las variables sexo y tipo de estudio lo que se buscaba era una distribución de la muestra en que no quedara sobrerrepresentado ningún tipo de estudiante. No obstante, la categoría central en el diseño muestral ha sido, como cabría esperar, la posición de clase, por lo que el análisis se orientó a la saturación de los discursos enfatizando especialmente esta dimensión.

La estrategia metodológica que hemos seguido se ha apoyado en el análisis de los discursos de los sujetos entrevistados, tanto sobre los aspectos más académicos (por qué estudian en la universidad, trabajo académico, preocupación por las notas, organización del tiempo, el precio de las matrículas, previsión de finalización de estudios, y planes de futuro), como a los más sociales, relativos a sus condiciones de vida (de qué viven, dónde viven, si trabajan o no y por qué, el sentido que les dan a las becas, 
dependencia de los padres). Las entrevistas han sido abiertas $o$ semiestructuradas, y por ello no se puso el foco muy directamente en el tema de las becas, sino que más bien se fue dejando a los entrevistados que dieran forma a su discurso, a partir de una alusión general a los modos de financiación de sus carreras con los gastos que conllevan.

Queríamos acercarnos al mundo universitario a través de la "experiencia" (Bertaux, 1993) que de él poseen los estudiantes, que son parte y producto de ese mundo, y en última instancia reconstruir los marcos interpretativos desde los que los sujetos confieren sentido a sus prácticas como estudiantes universitarios que son o en algún momento han sido becarios. Nuestros datos primarios serán, pues, decires, información cualitativa, que nos servirá para saber más de los incipientes efectos cuantitativos del giro en la política de becas implementado a partir de un momento en que además se optó por una subida muy relevante de los precios de los estudios universitarios. Esperamos que nuestra aportación sea de algún modo sustantiva a la hora de informar sobre las actuales constricciones materiales y académicas que afectan a quienes dependen en mayor o menor grado de una beca, y sobre el modo en el que se desenvuelven las diferentes praxis y discursos de los estudiantes en un contexto en que las reglas de juego han experimentado importantes transformaciones que han configurado nuevas estructuras de oportunidades.

Pasemos sin más a describir algunos de nuestros principales hallazgos.

\section{Las Becas como Condición de Posibilidad de ser Universitario.}

Resulta muy recurrente y se expresa con gran claridad por parte de muchos de nuestros entrevistados el que las becas son la condición sine qua non de la apuesta universitaria. Corresponde este discurso a estudiantes conscientemente dependientes de la consecución y el mantenimiento año tras año de una beca, y que incluso se muestran por ello "apurados" en algún caso, como veremos.

Dije de hacer abogacía...Al principio no lo ves, buf. Lejos, superlejos porque dices tú ¿cómo voy a llegar a una carrera? Pero saqué el bachillerato y me presenté a selectividad y aprobé en ${ }^{8}$ la primera convocatoria...y pues nada, ya de ahí eché la preinscripción para Derecho, y como me dieron la beca el primer año pues, sin problemas, 


\section{Langa-Rosado-Becas y Estudiantes de Clases Populares}

todo bien (M, Derecho1) $)^{9}$.

De otro lado, y en relación con lo anterior, quisiéramos destacar que otro de los componentes centrales del significado de las ayudas tiene que ver con cómo éstas contribuyen a reducir la dependencia de los padres mientras se estudia y así aminorar el sentimiento de deuda que genera.

Entonces pues cuando ha trabajado ella (se refiere a su hermana, que trabaja temporalmente) ya se ha... se ha gastado sus cosas. Si ha tenido que comprarse ropa o lo que sea con su dinero hasta que ya no le ha quedado y entonces ya pues otra vez dependiendo de mis padres. Pero eso es lo mismo que me pasa a mí con la beca. Cuando a mí se me acabe pues ya si no encuentro trabajo dependeré de ellos $(\mathrm{V}$, Educación Infantil).

El siguiente relato ilustra igualmente este tipo de semantización. Se trata de un estudiante que cambió de Ingeniería informática a Historia porque a mitad de curso se dio cuenta de que la ingeniería no le gustaba nada, y que cuando empezó el segundo intento, ya sin beca, experimentó una enorme presión en forma de mala conciencia ante los padres por la apuesta costosa, $y$ fallida. De ahí que cuando ya en segundo de Historia recupera su condición de becario, nos dice que lo primero que hace es devolverle al padre el dinero "mal gastado" del primer año.

La beca para mí no es un premio a mis notas..., es lo que me ha permitido seguir estudiando. (...).

Sí. La recupero en segundo de carrera. De hecho, ya me dan una cuantía bastante importante, rozando los tres mil euros y lo que hago es devolverle esos novecientos, esos setecientos euros a mis padres del año que me pagaron ( $\mathrm{V}$, Historia).

Para quienes la beca constituye un recurso tan crucial en la opción universitaria, el miedo a no aprobar las asignaturas necesarias está muy presente en sus experiencias académicas. Resulta pues coherente que quienes viven así su relación con la beca, expresen en sus discursos un control exhaustivo del tiempo. A continuación, se muestra en este sentido la tensión entre asegurar el aprobado o ir a por notas. 
Sí hombre, yo intento sacar las mejores notas posibles, pero... también como me organizo para intentar aprobar todo de primera hora pues... hombre, si me dejara alguna asignatura... (V, GAP).

De otro lado, también la gestión del dinero es bastante calculada, no sólo de cuánto se gasta sino de a qué se destina. Se preocupan mucho de mostrar un uso legítimo, académicamente productivo, entre otras cosas porque se intentan desmarcar del estereotipo del becario despilfarrador que, como veremos, reproducen frecuentemente en sus discursos.

Mi madre dice que soy una calculadora que estoy todo el día ajustándome las cuentas. No hombre yo por ejemplo mis compañeros de piso tengo uno que su situación económica es quizás muy buena. Luego tengo otro que en mi misma situación y yo creo que el de mi misma situación echa cuentas. Salimos menos, gastamos menos... es la realidad. Si te dicen vamos a echar una cerveza "pues mira yo puedo salir a lo mejor a echar una cerveza, pero salir dos o tres días en semana ya no puedo". O esta tarde vamos a tomar un helado o no sé qué vamos a guardar los dos euros porque te pueden hacer falta para otra cosa" (V, Primaria2).

Yo, digamos, tengo mis cuentas bien diferenciadas (...). claro porque como no lo suelo tocar, porque luego cuando... que gastar de mi dinero sí gasto para estudiar digamos, pero del de estudios para mis gastos no... no cojo. (...).

P. ¿Para tus gastos cómo?

No... Me refiero...Me refiero para mis gastos no... para caprichos digamos. Como si me voy este fin de semana que voy a ir a un concierto, que eso no lo cojo yo... de la beca. Que hombre que yo conozco gente que le viene la beca y lo primero que hace es que se compra videoconsola, lo otro...y no, yo los dineros de estudiar son para estudiar (V, GAP).

\section{Las Nuevas Contingencias del Sistema. El colchón "Imprescindible" de la Familia y el Sentimiento de Deuda.}

Señalábamos al principio que el sistema de becas no tenía una amplia cobertura en nuestro país incluso antes de 2013. No obstante, las nuevas 


\section{Langa-Rosado-Becas y Estudiantes de Clases Populares}

condiciones de acceso y permanencia aún lo han debilitado más. No nos ha resultado nada extraño, pues, que sean muchas las manifestaciones de nuestros entrevistados que muestran cómo sus apuestas universitarias se asientan, sin menoscabar el papel importantísimo de las ayudas a los estudios, en el consentimiento y el apoyo con que cuentan de sus familias para realizar su andadura universitaria.

Hombre, si eso pues decir que sí, las becas influyen obviamente en la forma de... como te planteas la carrera o como no te la planteas mucha gente pero yo creo que más que las becas es el entorno en el que estés, o sea si la gente, los padres y demás te apoyan, es importante tener una beca sí pero que no es lo mismo que...la gente que está a tú alrededor no te apoye, que te apoye... (V, Biología).

Ahora se anticipa en mayor medida que el sistema de becas puede ser insuficiente, incluso en el caso de alumnos de solvente trayectoria académica. El siguiente fragmento corresponde una estudiante de Fisioterapia que expresa que su primera opción fue la Universidad de Jaén, pero no porque así ella lo prefiriera, sino porque allí vivían sus tíos; esto le ofrecía la garantía - nos explica- de cubrir posibles contingencias del sistema de becas. De nuevo la seguridad que la ayuda familiar confiere a las apuestas de estos estudiantes.

Y lo primero que eché fue en Granada porque la verdad que para el tema económico y eso, mis tíos viven allí. Y yo algunos años si hubiera tenido algún problema de... de estos económicos, que no pudiera mantener un piso aquí y... y lo que conlleva cuatro años de carrera pues podía haberme...como ido con ellos. Que me lo dijeron ellos, que si algún año tendría que irme allí con ellos pues que podría vivir con ellos, pero estaba muy alta en Jaén y me cogieron aquí y ya no... no lo pensé.

P. ¿Granada te hubiera venido mejor económicamente que esto?

Mientras pudiera... por ver si me daban beca por el tema de becas y esto pues... pues sí, sí me podría mantener ahí, pero si algún año no... no me la hubieran dado o hubiera tenido algún problema o algo mis tíos estaban ahí. (M, Fisioterapia).

$\mathrm{Si}$, ya no como anticipación sino en efecto, acontecen dificultades, $\mathrm{y}$ 
empiezan a bajar los resultados académicos y se pierde la beca, en muchos casos se echa mano a la ayuda de la familia, no desde luego con pocos costes para estos estudiantes que no asumen sin más la dependencia de los padres.

Cuando no he tenido beca, mis padres me han pagado la matrícula y yo he intentado por todos los medios coger apuntes, en vez de comprar libros o tener que fotocopiar, el pedirle a mis padres dame tanto para yo poder comprarme un libro cuando también sé que la economía de mi casa no está para comprarme un libro que valga cuarenta y pico o cincuenta y tantos euros...pues un libro pues no, pues tomo apuntes del profesor y yo me estudio en el examen esos apuntes, lo que haya podido coger... (M, Derecho1).

La sensación de deuda contraída con la familia no siempre se lleva de un modo relajado; al contrario, pensamos que la gestión exhaustiva de los tiempos y el dinero que describíamos más arriba tiene que ver mucho con esto. En otras ocasiones, la no posibilidad de este endeudamiento, o incluso la evitación del sacrificio que comportaría para la familia, hace que la estrategia del estudiante se apoye más en el colchón de "seguridad" que puede sentirse al tener un vínculo con el mundo del trabajo o de los trabajos, precarios, temporales y escasamente remunerados en muchas ocasiones, pero que "protegen" de las múltiples contingencias desfavorables que podrían empujar a estos jóvenes a abandonar y a desistir de sus apuestas educativas. El siguiente fragmento es muy expresivo de cómo la dependencia de los padres (no estar trabajando) es un costo que cobra su lado más crudo cuando no acompañan los resultados académicos. Trabajar en estos casos aminora el sentimiento de deuda.

Y luego ya pensabas: "Jolín vas avanzando no apruebas y encima tengo tanta edad...". Vamos tengo veintitrés años que no tengo... Y ni he trabajado en mi vida, vamos no he trabajado, he echado a mi padre una mano en la tienda, pero vamos eso no se puede llamar... Hay gente de mi edad que ya está trabajando, gente más joven que tiene su puesto de trabajo y tú vives de tus padres... (M, Ingeniería Civil).

El discurso que sigue corresponde a un chico que, además, es muy consciente de que compatibilizar los estudios con el trabajo implica una segura demora en la finalización de los estudios. Se trata de un estudiante 


\section{Langa-Rosado-Becas y Estudiantes de Clases Populares}

que se va a otra ciudad y reside en piso de estudiantes. No obstante, en $3^{\circ}$, con los cambios del decreto 2012, suspende tres asignaturas y pierde la beca y decide retrasar dos años las trece asignaturas que le quedan para acabar el grado, por asegurar el éxito y no pagar matrículas más caras. La dedicación a cuidar ancianos algunas noches le hace sentirse mejor con respecto a su familia, de la que es consciente depende su permanencia en la universidad a pesar de los contingentes inconvenientes que a lo largo de su carrera han ido surgiendo (“ayudar a mis padres a mantenerme allí').

Lo que hice fue partírmelo en...en dos años y compaginé el estar en la facultad con trabajar.

P. ¿Pero y dos años te hacían faltan, si más o menos tu habías ido sacándolo...el año o los años limpios hasta el momento...?

Si... pero lo veía... es como que al no tener esa ayuda pensé cogerme menos créditos, a lo mejor dedicar un poco de tiempo a trabajar, que lo que me dediqué fue a cuidar ancianos por las noches y...ese poquillo dinero ese poquillo tiempo que perdía a lo mejor era dinero que podía ayudar a mis padres a mantenerme allí el piso y demás. Vamos que es para lo que lo utilicé. Lo utilicé para pagar gastos más que... el piso es que era más caro pero lo que son los gastos a lo mejor de facturas lo pagaba con lo que ganaba cuidando personas mayores (V, Biología).

Otras veces las razones que se arguyen para trabajar tienen que ver con la insuficiencia del aporte de la beca y el retraso en su cobro efectivo.

El tema de la beca es muy complicado para según qué persona ¿sabes? Porque tú ten en cuenta, yo me excedo un tope, por unos cien o doscientos euros por el cual no me dan mil o mil quinientos euros más y yo tengo que trabajar porque no me dan beca hasta abril. $\mathrm{O}$ sea, yo ganaría más dinero, más dinero de beca que trabajando y no puedo dejar de trabajar porque me dan la beca en abril. O sea, que si no trabajo no vengo, pero si no trabajara me darían más dinero, o sea que fíjate lo poco pensado a la realidad que está pensado muchas veces el servicio de becas ¿sabes? (V, Educación Social).

En cualquier caso y resumiendo, la pérdida de las ayudas sitúa a los estudiantes en la necesidad, más o menos costosamente sobrellevada, de 
incrementar la dependencia de los padres. Hay quienes empiezan por ello a trabajar, o incluso hemos visto quienes han tomado la decisión de hacerlo antes, como forma de defenderse de las contingencias del sistema de becas. Todo ello está además muy modulado por el nivel de costes que implica estudiar, que depende de múltiples factores o circunstancias: de si se vive más cerca o menos del campus; de la situación económica familiar; de los resultados previos (más o menos prometedores); del nivel de dificultad de la carrera, y de la exigencia de presencialidad. Hemos establecido una divisoria entre quienes empiezan a realizar algún trabajo como opción transitoria hasta que se recupera la beca, o quienes definitivamente, una vez que han tomado contacto con el mercado laboral, a pesar de las limitaciones que implica de cara a asumir el rol académico de estudiante, prefieren no perder el respaldo de unos ingresos extra que les permiten negociar de un modo más confortable la dependencia de los padres, y con ello ganar flexibilidad en una apuesta que se intuye, además, como veremos a continuación, larga e incierta.

\section{Estudiar Significa Ahorrar. Entre el Ahorro y el Mito del Becario Despilfarrador.}

El estereotipo del becario despilfarrador, o fraudulento en el uso de las becas, que se ha convertido en todo un recurso en el argumentario a favor de la actual reforma del sistema de becas, tiene un amplio predicamento entre los propios perceptores de ayudas. Ahora bien, lo que nosotros encontrarnos entre los becarios, frente a lo que la imagen de este estereotipo proyecta, es una actitud de una calculada gestión en el uso de los tiempos y el dinero, que antes señalábamos, y no sólo esto, sino una preocupación muy extendida por ahorrar ${ }^{10}$ parte de las ayudas percibidas.

Pues mira por ejemplo el hacer viajes con mis compañeras. Es que muchos de ellos por ejemplo en el verano se van a... "Vámonos a tal sitio" y... pues yo no, yo digo que no. Pues yo me quedo porque si no vamos a ver, me gasto la beca y entonces que hago para el siguiente año ¿Me toco la nariz? Pues no. (V, Educación Infantil).

Para los becarios estudiar implica ahorrar. La actitud de ahorro protege de las contingencias del sistema de becas: que no te la den, que te ingresen 


\section{Langa-Rosado-Becas y Estudiantes de Clases Populares}

tarde, o en menor cuantía de lo esperado.

Estás ya a mitad el curso, vamos a finales del primer cuatrimestre y todavía no... no te han dicho totalmente... Vamos, te dicen una media porque hace dos años, el año pasado no, otro. Es que como me han dado también beca en otros años a parte de... Ah, fue el primero, primero. No. Ya no sé qué año fue. Pero yo me acuerdo de habérmela dado en febrero. Y hasta marzo ¿sabes? Y hay gente que he oído que hasta abril o mayo tampoco (...).

Claro. Lo voy guardando y al año que viene, por ejemplo, yo ahora mismo estoy usando el del año pasado. Porque yo no sabía si... porque el año pasado no sabía si me iban a dar beca o no entonces...voy a seguir ahorrando para el año que viene y para el año que viene y así...Porque claro, por eso, porque tú no puedes saber lo que te van a dar, ni cuándo, y no puedes planificarte (M, Enfermería).

El imperativo ahorrador del estudiante becario se muestra además especialmente incardinado en una tensa valoración del futuro, una vez acabado los estudios, y ante un horizonte laboral gobernado por la incertidumbre y la necesidad de seguir apostando por la acumulación de capital educativo ${ }^{11}$. La apuesta universitaria, en efecto, se intuye se prolongará más allá del grado y tener un "colchón" que garantice una cierta estabilidad desde la que comprometer, o al menos planificar, decisiones futuras parece ser muy valorado.

De inglés es que todavía me tengo que apuntar, pero claro yo si me apuntara a una academia el dinero lo sacaría de ahí. Ya si los cursos también es lo que pagas con ese dinero y yo también en parte ese dinero lo utilizaré para cursos (M, Fisioterapia). Cojo otros ochocientos, novecientos para costearme el autobús y una parte la guardo. Unos setecientos u ochocientos euros la guardé en mi cartilla. En tercero igual, me dieron la beca, la guardé. Me pagué mis gastos de autobús y eso. $\mathrm{Y}$ en cuarto igual. $\mathrm{Y}$ entonces junté una cantidad de dinero que de hecho es lo que ahora no me ha impedido seguir estudiando el máster en otra ciudad (V, Historia).

En la faceta más pragmática de los discursos, o sea, cuando los estudiantes nos hablan de lo que hacen con las becas, estamos identificando 
un discurso donde se muestran muy claramente las nuevas limitaciones que el sistema actual les genera. No obstante, en la dimensión no tanto de los "haceres", sino en la más ideológica de los “decires" (Martín Criado, 1998), resulta paradójico cómo a pesar del enorme esfuerzo tanto académico como económico que estamos viendo despliegan los becarios, éstos muestran expresiones bastante conniventes con ciertos aspectos de la reforma. Nos ha sorprendido el modo en que algunos de nuestros informantes, lejos de valorar estas reformas críticamente, han intentado mostrarse comprensivos con las razones que justificarían las mayores exigencias. Subyace en muchas de las opiniones el tema de la escasez presupuestaria como ocasión para virar hacia un sistema más competitivo, lo que en el siguiente fragmento además se expresa como un cierto ejercicio de idealización: parece querer atribuir a los cambios un giro de mayor justicia social.

En el segundo de carrera sí es verdad que me soltaron de golpe y porrazo ahí toda la cantidad tres mil y pico euros... a partir de tercero sí que me cambió el sistema, es verdad ahora lo digo, cambió, porque al principio te daban mil quinientos euros y entonces había como tres fases. Una fase en la que todo el mundo recibía sus mil quinientos euros, en la segunda fase el dinero que había quedado entre los que más lo necesitaban se repartían otros mil quinientos euros y otra tercera fase en lo que ya lo que quedaba se repartía un poco también quién más lo necesitaba todavía. Entonces, ese modelo de repartir el dinero así sí que me pareció mucho más correcto que el que me hicieron a mí en segundo porque te implica... que no lo gastes todo, como digo yo que no lo fundas... porque yo conozco de casos de que cogían los tres mil euros y hacían... desde fiestas, coche, motos... despilfarrarlos o sea el dinero de las becas no iba para las becas $(\mathrm{V}$, Historia).

Las transformaciones acaecidas a partir de 2013 han condicionado más las ayudas al rendimiento, ya lo hemos visto, afectando esto de un modo especial a aquellos estudiantes que ya de por sí vivían sus apuestas educativas con una mayor dependencia del logro. Entre los becarios está muy asumido el discurso meritocrático, barnizado incluso de un tono moralizante, sobre el que expresan a veces una ciega adhesión (Río-Ruiz et al., 2014). Todo ello dificulta - pensamos- la explicitación de los factores estructurales de la desigualdad que intervienen en lo educativo y por tanto el 


\section{Langa-Rosado-Becas y Estudiantes de Clases Populares}

sentido equitativo del sistema de becas y ayudas. No parece en general que se tenga mucha idea sobre la función social de las becas y no hemos apreciado, salvo en contadas excepciones, una opinión crítica y elaborada sobre los cambios en el sistema. No obstante, insistimos, nuestros informantes nos informan recurrentemente sobre las constricciones y contingencias que las nuevas reglas generan. Entendemos este desfase entre las expresiones ideológicas y los discursos más pragmáticos sobre las becas como un síntoma de una representación cada vez más privatista de la educación, un debilitamiento de la concepción de ésta como derecho ciudadano.

\section{Conclusiones}

Nuestra aportación ha querido acercarse a los sentidos que les dan los estudiantes de clases populares a las becas. Partimos de la hipótesis de que el descenso en las matriculaciones de grado a partir de 2013 tiene que ver en parte con la política universitaria más reciente. Nuestro trabajo muestra en este sentido regularidades discursivas que nos informan de viejas y nuevas tendencias en los modos de asumir la vida universitaria de jóvenes de clase baja, en el contexto de la reforma de las becas, y de los precios. Habrá que seguir rastreando cuantitativamente cómo repercuten estos cambios institucionales en tasas de matriculación, abandono, etc., en los distintos perfiles sociales. Ello nos permitirá contrastar el grado de plausibilidad de nuestra hipótesis que además, no pretende jugarse su validez externa en el terreno de la estadística, sino en el de la fecundidad interpretativa; ésta sólo puede darse a partir del uso de técnicas que permitan, a través del despliegue discursivo de los sujetos, reconstruir las razones prácticas, o razonabilidades, que orientan sus praxis. Esperemos que estas conclusiones aporten alguna claridad al actual panorama.

Hemos identificado, en este sentido, un tipo de discurso donde se expresa muy claramente que la beca es la condición que posibilita la apuesta universitaria, que se entiende muy costosa y que supone depender por un tiempo prolongado de la familia. Las becas constituyen un modo de aminorar esta dependencia y el sentimiento de deuda a ella asociado, lo que hace que su consecución y mantenimiento se conviertan en asuntos de vital importancia a la hora de continuar estudiando. Esto ya lo habíamos señalado 
en otros trabajos (Langa-Rosado y David 2006, Langa-Rosado y Río-Ruiz, 2013) y ha sido confirmado en análisis posteriores efectuados ya en el contexto del sistema tras las recientes reformas (Río et al., 2014, 2015). En este nuevo escenario quizá es donde haya que ubicar las recurrentes/contundentes declaraciones de los becarios en torno a la necesidad precisamente del colchón de la ayuda familiar para hacer frente a las contingencias e incertidumbres del sistema (becas insuficientes, concedidas tardíamente, cuyo importe se desconoce hasta el final de curso; o pérdida de becas con los nuevos criterios más sujetos al logro académico). No obstante, el grado de posibilidad de contar con los recursos familiares, que se valora muchas veces además como "sacrificio" por parte de los padres, depende de múltiples factores que tienen que ver con el nivel de coste que implican los estudios y las posibilidades reales de las familias, muchas de las cuales han visto mermada su situación socioeconómica a resultas de la crisis. La compatibilización del estudio con algún trabajo supone, para quienes no pueden asumir sin más aumentar la dependencia familiar, una forma de ir gestionando las nuevas dificultades, si bien en ocasiones a costa de prolongar unas carreras de las que empiezan a sentir su pesadez, por los múltiples e inciertos obstáculos que las van jalonando. Esta sensación de contingencia en los estudios se extrapola también a su visión del porvenir, cada vez más inseguro, pero desde luego necesitado de continuidad en inversión educativa (Langa-Rosado Rosado, 2018). De hecho los alumnos que reciben mayor cuantía en sus becas, que suelen ser además bastante explícitos en su dependencia de ellas, expresan una firme voluntad ahorradora del dinero de las ayudas en previsión de futuras inversiones una vez concluido el grado, o de contingencias durante el propio curso. A pesar del enorme esfuerzo del que los becarios nos informan en las entrevistas, resulta aparentemente paradójico la persistencia con que se reproduce en sus discursos el estereotipo del becario despilfarrador. Esto está en la base pensamos- de un tono connivente con ciertos aspectos de la reforma, que apunta a la sólida adhesión al discurso meritocrático, con tintes moralizantes incluso, que exhiben estos jóvenes cuando expresan su opinión sobre las recientes transformaciones en el sistema. Un sistema que vincula más la posibilidad de estar en la universidad al rendimiento del estudiante (no sólo en las becas, también en los precios de matrícula) y que con ello redobla la dependencia que éste tiene del logro, tantos en sus elecciones como a lo 


\section{Langa-Rosado-Becas y Estudiantes de Clases Populares}

largo de la carrera, como señalábamos al principio. Queremos subrayar finalmente la escasa valoración crítica, a nivel ideológico, que exhiben los entrevistados acerca del alcance de estos cambios de los que, por el contrario, nos informan en sus discursos con bastante crudeza sobre las nuevas y contingentes dificultades que han ocasionado. Nos parece que esta aparente contradicción puede leerse como un síntoma que apunta a un rasgo del nuevo momento del ciclo socioeconómico del capitalismo informacional (Martínez Celorrio, 2002) o incluso del ciclo político (Aja Valle, 2016), en que las oportunidades educativas, lejos de funcionar como un elemento de consenso, por el contrario, se ubican en un escenario más competitivo, de cierre social, y en que la educación pasa a concebirse menos como un derecho y más como un recurso privado, dependiente de los méritos personales y/o la capacidad económica de adquirirlo.

\section{Notas}

${ }^{1}$ Un poco antes, con la adaptación al Espacio Europeo de Educación Superior en 2010, se introdujo la novedad de diferenciar los precios de los grados y los másteres, que son actualmente un $67 \%$ más caros.

${ }^{2}$ Relación porcentual entre créditos superados y matriculados.

${ }^{3}$ Relación porcentual entre créditos superados y presentados.

${ }^{4}$ Relación porcentual entre créditos presentados y matriculados.

5 Aún más en la universidad privada

6 El trabajo se sitúa en el marco del proyecto UJA2014/06/33 subvencionado por la Universidad de Jaén y la fundación Caja Rural de Jaén (RFC/Acción6_2014).

7 Todos los estudiantes de origen popular han sido becarios, 15 de ellos nunca han perdido esta condición, y 12 lo han sido intermitentemente. Hay cuatro entrevistados de clase media, que hemos utilizado como contraste.

${ }^{8}$ Pensamos que la técnica de la entrevista abierta es justo en el decir sobre el hacer, más que en la reproducción del discurso ideológico, donde suele mostrarse más fecunda (Alonso, 1999).

9 Todas las citas llevarán la información de si el entrevistado es varón (V) o mujer (M), además de la titulación que cursa.

${ }^{10}$ Obviamente, esto se manifestará más entre los becarios que perciben mayor cuantía, que en nuestros entrevistados coinciden con los más dependientes de las ayudas en sus apuestas educativas.

${ }^{11}$ En Langa-Rosado Rosado (2018) señalaba como una nueva dificultad en las apuestas de los estudiantes de clases populares la gestión de la incertidumbre con que cada vez se percibe más tanto la apuesta universitaria como su posible beneficio. 


\section{Referencias}

Ariño, A. (2014). La dimensión social de la Educación Superior. RAS, 7(1), $17-41$.

Aja, J. (2016). Clase, precariedad laboral y crisis de régimen. Desde abajo, 5, 49-56.

Alonso, L. E. y Callejo, J. (1999). El análisis del discurso: del postmodernismo a las razones prácticas. REIS, 88, 37-73.

Archer, L., Hutchings, M. y Ross, A. (2003). Higher Education and social class. London: RoutledgeFalmer.

Berlanga Silvente, V.; Figuera Gazo, M. P. y Pons Fanals, E. (2018). Modelo predictivo de persistencia universitaria: Alumnado con beca salario. Educación XXI, 21(1), 209-230. doi: 10.5944/educXX1.20193

Bertaux, D. (1993). La perspectiva biográfica: validez metodológica y potencialidades. En: J. M. Marinas y Santamaría, C., La historia oral: métodos y experiencias. Madrid: Debate.

Bourdieu, Pierre (1997). Razones prácticas. Madrid: Anagrama.

Cabrera, L., Bethencourt, J. T. González, M. y Álvarez, P. (2006a). Un estudio transversal retrospectivo sobre prolongación y abandono de estudios universitarios. Relieve, 12(1), 105-127.

Cabrera, L., Bethencourt, J. T. González, M. y Álvarez, P. (2006b). El problema del abandono de los estudios universitarios. Relieve, 12(2), 171-203.

Carabaña, J. (2018). Los efectos de la crisis sobre el sistema escolar. RES, 27 (1), 109-112. doi:10.22325/fes/res.2018.6

Callender, C. y Jackson, J. (2008). Does the fear of debt constrain choice of university and subject of study? Studies in Higher Education, 33(4), 405-429.

CCOO Enseñanza (2016): Los precios de las matriculas universitarias. Becas, ayudas y beneficios fiscales en Europa. La evolución de los precios públicos del sistema universitario español entre 2011 y 2016 Recuperado de http://www.um.es/ccoo/images/2016/Informe\%20Precios\%20Publicos $\% 200 K \% 2018-04-2016 . p d f$

Delapierre, F. (2015). La bomba de la deuda estudiantil. Barcelona: Icaria.

Finkel, L. y Barañano, M. (2014). La dedicación al estudio y al trabajo de 
los estudiantes universitarios en España. RASE, 7(1), 82-103.

Hernández, J. y Pérez, J. A. (2014). La Universidad española en cifras, 2014/2015.CRUE Universidades españolas.

Hernández, J. y Pérez, J. A. (2017): La Universidad española en cifras, 2015/2016.CRUE Universidades españolas.

Herrera, D. (2019). ¿Quién estudia en la universidad? La dimensión social de la universidad española en la segunda década del siglo XXI. RASE, 12(1), 7-23. doi: 10.7203/RASE.12.1.13177

Isleib, S. (2017). How educational background is shaping (types of) Higher Education Dropout. Paper presentado en la Conferencia ECER 2017, Copenhaghe. Recuperado de http://www.eera-ecer.de/ecerprogrammes/conference/22/contribution/41111/

Langa-Rosado Rosado, D. (2015). La Universidad: los alumnos En Carabaña, J. (coord.), España 2015. Situación social. Madrid: CIS.

Langa-Rosado Rosado, D. (2018). La apuesta universitaria en los jóvenes de clases populares. Entre la promoción social y la falta de horizonte. RES, 27 (1), 137-145. doi: $\quad 10.22325 /$ fes/res.2018.9

Langa-Rosado, D. y David, M. (2006). A 'massive university or a university for the masses':Continuity and Change in Higher Education in Spain and England. Journal of Education Policy, 21(3), 343365.doi: 10.1080/02680930600600630

Langa-Rosado, D. y Río, M. (2013). Los estudiantes de clases populares en la universidad y frente a la universidad de la crisis: persistencia y nuevas condiciones para la multiplicación de la desigualdad de oportunidades educativas. Tempora, 16, 71-96.

Martínez Celorrio, X. (2002). Educación, cierre social y nuevas políticas de acceso al conocimiento. Tempora, 5, 89-102.

Martín Criado, E. (1998). Los decires y los haceres. Papers, 57, 57-71.

Martín Criado, E. y Gómez Bueno, C. (2017). Las expectativas parentales no explican el rendimiento escolar. RES, 26(1), 33-52. doi: $10.22325 /$ fes/res.2016.2

Martínez García, J. S. (2014). Clase obrera, género y éxito educativo: inteligencia, expectativas y didáctica. RASE, 7(2), 449-467.

Metcalf, H. (2003). Increasing inequality in higher education: the role of term time working. Oxford Review of Education, 29(3), 315-329. doi: $10.1080 / 03054980307447$ 
Ministerio de Educación, Cultura y Deporte (2017). Datos y Cifras del Sistema Universitario Español. Curso 2015-2016. Madrid: Subdirección General de Documentación y Publicaciones.

Mingat, A. y Eicher, , J.C. (1982). Higher Education and employment markets in France. Higher Education, 11 (2), 211-220. doi:10.1007/BF00139689

Reay, D. David, Miriam., D.\& Ball, S. (2005). Degrees of Choice: social class, race and gender and gender in higher education. Stoke-onTrent: Trentham Books.

Río-Ruiz, M. (2014). Efectos de la conversión en becario y consecuencias de la reforma del sistema de becas entre universitarios de clase obrera. RASE, 7(2), 468-487.

Río-Ruiz, M., Jiménez-Rodrigo, M. L. (2014).Las becas 6000 a examen. Resultados, prácticas, expectativas y oportunidades escolares de familias y estudiantes incluidos en el programa. RIS, 72(3), 609-632. doi:10.3989/ris.2013.03.05

Río-Ruiz, M., Jiménez-Rodrigo, M. L. y y Caro-Cabrera, M. J. (2015). The shifting financial aid system in Spanish University: grantrecipients'experiences and strategies. Critical Studies in Education, 56(3), 332-350.

Sacristán, V. (2014). El cost d'estudiar a Europa. Preus, beques, préstecs $i$ ajuts a les universitats europees (2013-2014). Barcelona: Observatory sistema universitari.

Torío López, S., Hernández García, J. y Peña Calvo, J.V. (2007). Capital social familiar y expectativas académico-formativas y laborales en el alumnado de Educación Secundaria Obligatoria. Revista de Educación, 343, 205-208.

Torrents, D. (2015). Trayectorias juveniles y factores de la demanda de educación universitaria española para el año 2009. Papers. Revista de Sociología, 100(1), 131-149. doi: 10.5565/rev/papers.623

Torrents, D. (2016). La autopercepción de las capacidades: origen social y elecciones educativas.RASE, 9 (1), 78-93. Troiano, H., y Elias, M. (2013). University access and after: explaining the social composition of degree programs and the contrasting expectations of students. Higher Education, 67, 637-654. doi: 10.1007/s10734-013-9670-4

Troiano, H., Torrents, D. (2018). La evolución del acceso a la universidad en 
126 Langa-Rosado - Becas y Estudiantes de Clases Populares

Cataluña: ¿Cómo la explicamos?”. Revista Española de Sociología, 27(1), 127-136. doi:10.22325/fes/res.2018.8

Troiano, H., Torrents, D., Sánchez-Gelabert, A. y Daza, L. (2017). Evolución del acceso a la universidad entre la población joven en Cataluña. Cuaderno de Relaciones Laborales, 35(2), 281-303.

Triventi, M. (2011). Stratification in higher education and its relationship with social inequality: A comparative study of 11 European countries. European Sociological Review, 29(3), 489-502. doi: 10.1093/esr/jcr092

Triventi, M. (2014). Does working during Higher Education affect student's academic progression? Economics of Education Review, 41, 1-13. doi: 10.1016/j.econedurev.03.006

Villar Aguilés, A. (2010). Del abandono de estudios a la reubicación universitaria. RASE, 3(2), 67-283.

Delia Langa-Rosado is professor at the University of Jaén, Spain Contact Address: dlanga@ujaen.es 